Revista Mexicana de Economía y Finanzas, Vol. 8, No. 2, (2013), pp. 157-180

\title{
FINANCIAL INCLUSION INDEX: PROPOSAL OF A MULTIDIMENSIONAL MEASURE FOR MEXICO
}

\author{
César Manuel Zulaica Piñeyro* \\ Instituto Tecnológico Autónomo de México \\ Primer Lugar en el Premio IMEF-Ernst \& Young 2012, Categoría de Tesis
}

(Received April 19, 2013, accepted July 25, 2013)

\begin{abstract}
The main purpose of this paper is introducing an index that allows for a general overview of Mexico's municipalities in terms of financial inclusion. The index is calculated using principal component analysis on variables related to the measurement of the levels of access and usage of financial services, financial education, consumer protection and social development. Subsequently, all municipalities are ranked by an estimated degree of inclusion performing hierarchical cluster analysis. Results show that $36 \%$ of Mexico's municipalities possess a high level of financial inclusion while $29 \%$ the lowest. Municipalities with higher income and better education benefit from the services that financial institutions offer, yet millions are still excluded from the financial system.
\end{abstract}

\section{Resumen}

El objetivo de este trabajo es proponer un índice que permita tener un panorama general de cada uno de los municipios de México en términos de inclusión financiera. Con variables pertenecientes a la medición del acceso y uso de servicios financieros, educación financiera, protección al consumidor y desarrollo social, el índice se obtiene a través del análisis en componentes principales. Posteriormente, se clasifica a los municipios con ayuda de un análisis de conglomerados jerárquico. Los resultados muestran que $36 \%$ de municipios tienen inclusión alta, $35 \%$ media, y el resto (29\%), baja. Al realizar un análisis, se concluye que la población con ingreso y nivel educativo mayor es aquella que se beneficia de los servicios financieros, mientras que millones de personas se encuentran excluidas del sistema financiero.

JEL Classification: 040, C65, D63

Keywords: Financial Inclusion, Principal Component Analysis, Multidimensional Measure

* Río Amazonas No. 16, C.P. 06500, Tel: +5215551398821. Col. Cuauhtémoc, México, D. F. E-mail: cesarmzp@gmail

The author is very grateful to the anonymous referees for their comments and careful research assistance from Karla González is duly acknowledged. 


\section{Introduction}

Financial inclusion is defined as the access and usage of financial services under appropriate regulations to ensure consumer protection schemes and promote financial education such that it improves the financial capabilities of all segments of the population. ${ }^{1}$ Although there is no global consensus on its definition, it is clear that financial inclusion has the characteristic of being a multidimensional phenomenon, and literature of recent years has been dedicated to define new ways of measuring, understanding and expanding its study worldwide, especially in developing countries.

As of today, there are numerous indicators that describe the different dimensions of financial inclusion individually; however, there is currently no measure designed to rank, in terms of financial inclusion, the situation of the municipalities or states of Mexico. Studying the number of bank branches on a specific location or the number of adults with a formal (regulated institution) bank account or credit card, allows to describe the dimension to which the variables pertain (access and usage, respectively) but does not, in any way, provide a junction between both dimensions to let us know whether a municipality with a number of bank branches and accounts is more included or excluded than the rest of the country's administrative units. ${ }^{2}$

On this basis, the need of capturing the different dimensions of this phenomenon on a financial inclusion index is born. Subsequently, this paper presents, with aid of the index, a classification of the municipalities according to a certain degree of financial inclusion, and therefore, detecting that there are pronounced differences and similarities between certain groups of municipalities, states and regions.

It is also considered that this document will be of future reference for financial institutions and regulatory entities in the financial sector seeking to propose alternatives and policies that help provide more and innovative financial services to all segments of the population who do not have them and can benefit from their correct use.

The study is divided into the following sections: section 2 describes previous efforts from other countries to measure financial inclusion as a multidimensional phenomenon; section 3 defines the dimensions of financial inclusion used in this paper and the institutions that are included as part of the study; section 4 describes the methodology applied to calculate the index and classify Mexico's municipalities according to their degree of financial inclusion; section 5 presents the advantages and disadvantages of the proposed index; section 6 describes a general overview of financial inclusion in Mexico as an introduction to the results of the index; section 7 , the main results at a municipal, state, and regional level; finally, section 8 concludes.

\footnotetext{
1 Secretaría de Hacienda y Crédito Público (2011), Acuerdo por el que se crea el Consejo Nacional de Inclusión Financiera, Diario Oficial de la Federación, October 3, Mexico, p. 1.

2 As of 2012, Mexico has 2,456 municipalities (administrative units) distributed in 32 states.
} 


\section{Previous Findings}

Proposals of a financial inclusion index that allow comparisons between geographical divisions or countries around the world have been developed previously in India and Brazil. In the first example, an index of financial inclusion was constructed to find differences between countries. Developed by Mandira Sarma, ${ }^{3}$ this index brings forward three dimensions of an inclusive financial system: banking penetration, availability of banking services and usage of the banking system. ${ }^{4}$ These dimensions were motivated by the availability of relevant and consistent data for a large number of countries. Sarma's index is computed as the normalized inverse Euclidean distance of weighted observations to an ideal point with an upper value limit of the empirically observed 94th quantile. The limitations of this proposal include that it only uses banking information, that the dimensions are weighted subjectively, and that values greater than the 94th quantile are set equal to it.

A second effort for a financial inclusion index was presented by Brazil. This other index is computed using the same formula and dimensions that Sarma determined, but including 18 different variables. Nonetheless, even with these proposals, there is yet no tool to understand the phenomenon as a whole for the particular case of Mexico and each of its geographical divisions.

\section{Dimensions of Financial Inclusion and Institutions Studied}

Considering the possibility of constructing a financial inclusion index requires the definition of two areas: the financial institutions that will be part of the analysis, and the dimensions selected to describe the phenomenon.

According to the information gathered, the universe of financial institutions includes: banking institutions, correspondent banking agents (which serve as an extension of the banking services) and the Cooperative and Microfinance institutions that are supervised by the National Banking and Securities Commission (CNBV, in Spanish), Mexico's regulatory entity for this kind of institutions. When more detailed information is available at a municipal level, the universe of these financial institutions can be broadened ${ }^{5}$ to effectuate a more comprehensive study taking advantage of the data.

The main dimensions used to describe the phenomenon must be those measurable and quantifiable. For this study, financial inclusion is considered to be composed by four basic dimensions: access (infrastructure), usage (financial products), financial education and consumer protection. Also, a fifth additional dimension has been included: social development. The reason for including such dimension is that financial inclusion should not only take into account the number of bank branches or financial products in a country, but to study

\footnotetext{
3 Sarma, Mandira (2010), Index of Financial Inclusion, Discussion Paper 10-05, Jawaharlal Nehru University, India.

4 This index is computed with five variables: number of bank accounts as a proportion of the adult population, bank branches per 100,000 adults, number of ATM's per 100,000 adults, volume of credit as proportion of the country's GDP and volume of the deposits as proportion of the country's GDP.

5 The study could be extended to insurance and investment companies, and other deposit or credit institutions.
} 
the relationship between these variables and other social barriers that allow to further understand the limitations of individuals to access the financial system.

There are various methods for calculating an index: averages, intervals, distance measures, among others. The previous examples (India and Brazil's) are computed using the latter. In this paper, however, a different methodology is applied, which not only allows to preserve as much information of the variables as possible, but also aids in creating a new and easy to interpret variable (index).

\section{Methodology}

Creation of the index is achieved with information from the following sources: the 2011 regulatory reports and databases of the National Banking and Securities Commission $^{6}$ (CNBV); data of the 2010 Population Census and 2009 municipal statistics reported by the National Institute of Statistics and Geography (INEGI); indicators of the 2010 Statistical Yearbook of the National Commission for the Protection and Defense of the Users of Financial Services ${ }^{7}$ (CONDUSEF); dimensions pertaining to the 2010 poverty measurement of the National Council for Evaluation of the Policy of Social Development (CONEVAL); and finally, education indicators measured by the National Population Council (CONAPO) which were part of its 2010 marginalization index. Parting from these sources, 20 indicators were built for each of the 2,456 municipalities of Mexico, its 32 states, and five geographical regions. "These twenty indicators cover the five proposed dimensions (access, usage, financial education, consumer protection and social development).

Figure 1. Selected Variables by Dimension of Financial Inclusion

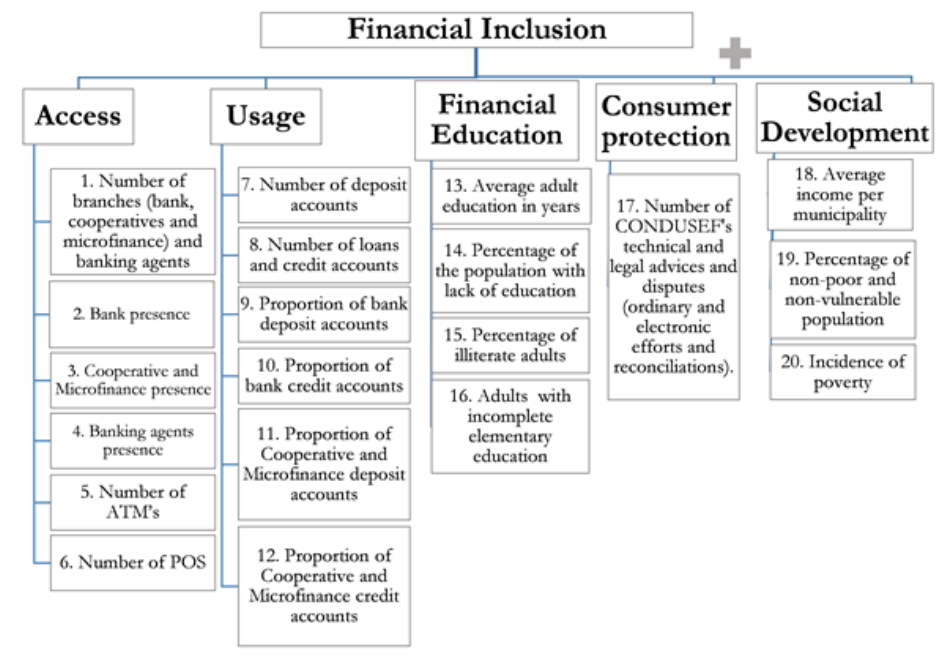

Fuente: Elaboración propia.

\footnotetext{
6 The Spanish abbreviations for these institutions are shown in parentheses.

7 Institution in charge of the consumer protection related with the users of financial services.
} 
Once the indicators were computed, principal component analysis was used to calculate the financial inclusion index. Such analysis allows reducing a number of variables which are highly correlated to a smaller number of uncorrelated variables that explain the phenomenon with the same information than the original indicators (retaining the variability of the data) but in a synthetic manner. Additionally, the results of this methodology provide the opportunity to find linear relationships between the original indicators, and determine whether they are correlated negatively, positively, or if there is no close relationship between them. An important feature that has to be taken into account when performing this type of analysis is the scale of the variables: if the scale of measurement of the variables is not consistent, it is advised to perform principal component analysis on standardized variables.

In other words, principal component analysis seeks to build a new set of synthetic variables called principal components, such that they are a linear combination of the original indicators under certain conditions:

( 1) The new variables must be uncorrelated: each principal component will describe a different characteristic of the dataset and not redundant information.

( 2) The new variables must have maximum variance: principal components account for most of the variance of the observed variables.

Therefore, each synthetic variable $\underline{c}$ is a linear combination of the observed variables such that:

$$
\underline{c}=X \underline{a}=\sum_{j=1}^{p} a_{j} x^{j}
$$

where $X$ is the matrix of the observed standardized variables and $\underline{a}$ is the weight vector associated with each of these variables. We are looking to maximize variance so:

$$
\max \operatorname{Var}(\underline{c}) \text { with the constraint } \underline{a}^{\mathrm{T}} \underline{\mathrm{a}}=1
$$

Nonetheless, to assess the variance of $\underline{c}$ it is necessary to obtain the function to be maximized:

$$
\operatorname{Var}(\underline{c})=\|\underline{c}\|_{D}^{2}=\underline{c}^{T} D \underline{c}=(X \underline{a})^{T} D(X \underline{a})=\underline{a}^{T} X^{T} D X \underline{a}=\underline{a}^{T} V \underline{a}
$$

where $V$ is the covariance matrix of the standardized variables. This matrix is invertible, symmetric positive definite $V=X^{T} D X$, and for standardized data, it corresponds to a correlation matrix. Naming $\underline{c}^{1}$ as the first principal component and $\underline{a}_{1}$ as the weight vector associated to the first component, we use the Lagrange multiplier technique to find the maximum of the objective function subject to the previously mentioned constraint ${ }^{8}$ and obtain the first solution:

$$
\mathcal{L}=\underline{a}_{1}^{T} V \underline{a}_{1}-\lambda_{1}\left(\underline{a}_{1}^{T} \underline{a}_{1}-1\right)
$$

the result is product of vector differentiation:

$$
\frac{\partial \mathcal{L}}{\partial \underline{a}_{1}}=2 V \underline{a}_{1}-2 \lambda_{1} \underline{a}_{1}=0
$$

\footnotetext{
8 Peña, Daniel (2002), Análisis de datos multivariantes, McGraw-Hill, Spain, pp 141-144.
} 
which implies that:

$$
V \underline{a}_{1}=\lambda_{1} \underline{a}_{1}
$$

showing that $\underline{a}_{1}$ should be chosen to be an eigenvector of $V$, say $\underline{a}_{1}$ with eigenvalue $\lambda_{1}$. But since the expression to maximize is $\operatorname{Var}\left(\underline{c}^{1}\right)=\underline{a}_{1}^{T} V \underline{a}_{1}=$ $\lambda \underline{a}_{1}^{T} \underline{a}_{1}=\lambda_{1}$, then $\underline{a}_{1}$ should be chosen as the eigenvector corresponding to the largest eigenvalue $\bar{\lambda}_{1}$ of $V$. Elements $a_{1 j}$ of vector $\underline{a}_{1}$ are called weights and they measure the importance of variable $j$ in principal component 1 . This definition applies to the rest of the principal components as well.

Now, in order to extract the second and remaining principal components, the function is now set to maximize the sum of the variance of those two (or more) components, subject to constraints $\underline{a}_{1}^{T} \underline{a}_{1}=1$ and $\underline{a}_{2}^{T} \underline{a}_{2}=1$. Therefore, the second solution is obtained from the following function:

$$
\mathcal{L}^{2}=\underline{a}_{1}^{T} V \underline{a}_{1}+\underline{a}_{2}^{T} V \underline{a}_{2}-\lambda_{1}\left(\underline{a}_{1}^{T} \underline{a}_{1}-1\right)-\lambda_{2}\left(\underline{a}_{2}^{T} \underline{a}_{2}-1\right)
$$

Once again, making use of vector differentiation:

$$
\begin{aligned}
& \frac{\partial \mathcal{L}}{\partial \underline{a}_{1}}=2 V \underline{a}_{1}-2 \lambda_{1} \underline{a}_{1}=0 \\
& \frac{\partial \mathcal{L}}{\partial \underline{a}_{1}}=2 V \underline{a}_{2}-2 \lambda_{2} \underline{a}_{2}=0
\end{aligned}
$$

the solutions obtained are $V \underline{a}_{1}=\lambda_{1} \underline{a}_{1}$ and $V \underline{a}_{2}=\lambda_{2} \underline{a}_{2}$, where $\lambda_{1}$ and $\lambda_{2}$ are the corresponding eigenvalues to $\underline{a}_{1}$ and $\underline{a}_{2}$, eigenvectors. Subsequently, evaluating the function with this solution implies that the variance will be the highest with the value $\lambda_{1}+\lambda_{2}$, concluding they correspond to the highest and second highest eigenvalues possible. Equivalently, matrix $V$ has $p$ distinct eigenvalues ( $p$ is also the number of original variables), so that $\lambda_{1}>\lambda_{2}>\ldots>$ $\lambda_{p}$.

After obtaining the results of principal component analysis, classifying the observations in groups whose members are similar and which have characteristics that distinguish them between groups is possible with aid from the components. To achieve this, performing a hierarchical cluster analysis using Ward's method is advised. Further in this paper, the method allows to classify the municipalities into three levels (degrees) of financial inclusion.

Hierarchical cluster analysis is a statistical method of partitioning data into homogeneous classes. In this analysis, each observation is part of a cluster or group (i.e. at the beginning there are as many groups as individuals) which is combined sequentially using a particular rule to reduce the number of clusters. The clustering method uses the dissimilarities or distances between objects when forming the clusters and, as a result, more and more groups are linked together creating clusters with increasingly dissimilar elements. As mentioned, a distance measure and a method for clustering must be approached. In the present text, Ward's method is used, computing Squared Euclidean distances. Ward's method for hierarchical cluster analysis indicates that two clusters will form a new one if the merging cost of combining those clusters will be minimal. 
Such merging cost is how much the sum of squares will increase when they merge.

Finally, an explanatory data analysis to distinguish the fundamental differences between each of these types of municipalities, the states, and geographic regions of the country can be performed.

\section{Advantages and Limitations of the Index}

The financial inclusion index computed in the following sections has the advantage of integrating major dimensions that have not been considered before by other countries when proposing a summary measure. Today, consumer protection and financial literacy represent a fundamental part of the policy agenda to broaden the use and access to financial services. The integration of these dimensions allows a more precise and profound comprehension of the analyzed phenomenon.

However, the index also reflects the need of improving the way data is reported by financial institutions. Hence, there are still a number of limitations that can be worked out in the near future. The first problem facing Mexico in terms of measurement is that the number of accounts cannot be individualized. So far, reports provided by financial institutions at a municipal level do not distinguish the number of people who have a specific account but offer the data on the number of accounts available. Very often, a person has multiple accounts for one or more types of products. Moreover, the universe of financial products included in the index can continue to expand. Products such as insurance and microinsurance, pension and investment accounts that are granted exclusively to individuals can be integrated in the calculation of this index, but need to be handed at a municipal level to be studied. To the extent that the information on these products is available, financial inclusion can be studied fully through an index.

\section{A Picture of Financial Inclusion in Mexico: Exploratory Data Analysis}

Prior to the construction of the index, it is convenient to perform an exploratory data analysis that can help to provide an overview on financial inclusion in Mexico.

According to 2011 data of the CNBV, approximately $44 \%$ of Mexico's municipalities have infrastructure coverage through banks, Microfinance branches and Cooperative branches. The implementation of banking agents as a business model has allowed to increase municipality coverage in $13 \%$ and the adult population with possibility of access in $4 \%$. Nonetheless, given the demographic distribution in the country, $90 \%$ of the adult population ${ }^{9}$ inhabits these municipalities. While rural municipalities have roughly 0.47 access points per 10,000 adults, metropolitan municipalities are attended by 4.37 .

Banks, Cooperatives and Microfinance institutions serve the population in Mexico through 14,537 branches, 12,486 banking agents, 36,098 ATM's and 500,294 point of service (POS) terminals. The demographic indicators

\footnotetext{
9 smalltype In the present study, adults are considered individuals of ages 15 and more.
} 
corresponding to these values allow for a better comprehension when linking them with the adult population: there are approximately 1.83 branches, 1.56 banking agents, 4.52 ATM's and 62.68 POS per 10,000 adults. For purposes of this paper, branches (bank, Cooperative or Microfinance) and banking agents altogether will be referred to as access points.

Out of all branches, $86 \%$ belong to banks while $14 \%$ belong to Cooperative and Microfinance institutions. When integrating the indicators for the deposit and credit services that these institutions offer, it is obtained that there are 11,742 deposit and 4,125 credit (loan) products per 10,000 adults. Of course, deposit accounts represent the most used financial service.

In terms of education and according to INEGI's 2009 municipal statistics, it is reported that the Mexican adult population attends an average of 8.1 years of schooling. CONEVAL, on the other hand, with its own study up to 2010 reports that $19.9 \%$ of the adult population has not completed primary education, while $6.9 \%$ of Mexico's population is illiterate. Complementarily, CONAPO informs that $20.6 \%$ of the Mexican population has an educational gap (referred to as lack of education), which is defined by not having complete compulsory basic education. Schooling is not only a fundamental tool for a person's daily life nowadays, but it has an impact on the socioeconomic conditions and the quality of life, because it allows people to access new knowledge, information, and implies greater opportunities for personal and professional development. Additionally, illiteracy plays it part: it limits an individual's participation in the society and increases their economic vulnerability, directly affecting the ability to get a job. The implications of these shortcomings are primarily economic and social. ${ }^{10}$

Moreover, in the dimension of consumer protection, CONDUSEF states in its latest statistical yearbook (2010) that in carrying out its duties, 1,086,999 actions of advisory work, management, conciliation, arbitration and free legal defense for the protection and defense of the users of financial services were executed. Promoting transparency in the formal financial sector is essential, so publishing these results is part of the tools that can be provided to the authorities, institutions and users to continue helping the cause.

Despite increased efforts, the reality of the Mexican financial inclusion has yet to reach wider segments of the population. The incidence of poverty ${ }^{11}$ is still a reality in the country. This large segment of the population, according to CONEVAL in 2010, is represented by $46.2 \%$ of Mexicans (52 million). These people, lacking income and the essential services, are even further away from accessing or acquiring a formal financial service that allows them to make better use of the income they receive, however small it may be. New policies and

\footnotetext{
10 Consejo Nacional de Población (2010), Índice de marginación por entidad federativa y municipio 2010, Mexico, p. 15.

11 CONEVAL states that the definition of poverty encompasses the living conditions of the population in three areas: economic welfare, social rights and the territorial context. Specifically, it refers to the population with an income below the welfare line, lack of rights related to health, social security, basic services, quality of living, education and food, as well as elements that transcend the individual and are associated with social cohesion.
} 
alternatives to attend this excluded segment must be created: financial services represent an opportunity.

Now that the national situation of each dimension has been outlined briefly, finding linear relationships between some of the variables provides a first view of the possible results. For this analysis, an indicator of each dimension was chosen: access points per 10,000 adults, deposit accounts per 10,000 adults, number of CONDUSEF's technical and legal advices and disputes per 10,000 adults and the percentage of the population in poverty conditions (or incidence of poverty). The results were obtained with SPSS Statistics 20

Figure 2. Scatterplot Matrix: One Variable per Financial Inclusion dimension.

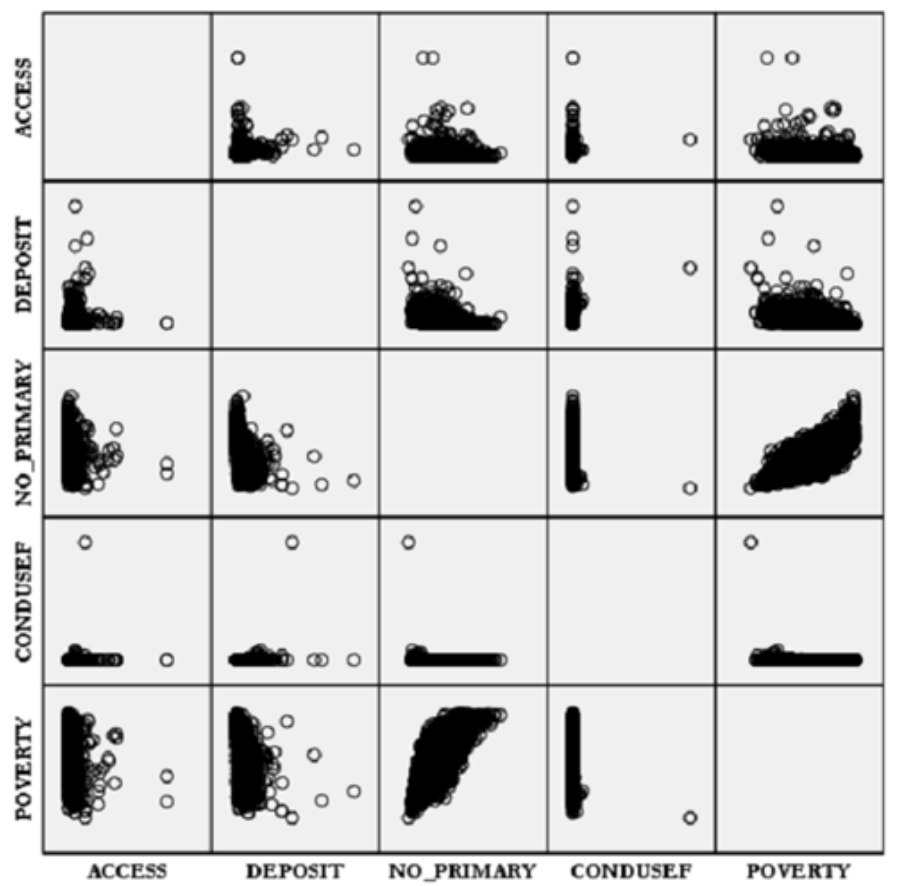

Fuente: Elaboración propia.

In the scatterplot and correlation matrices, two important details are spotted: first, a strong linear correlation between the adults with incomplete elementary education (NO_PRIMARY) and the population in poverty conditions (POVERTY); second, the indicators of access points (ACCESS), CONDUSEF's technical and legal advices and disputes (CONDUSEF) and deposit accounts (DEPOSIT) per 10,000 adults are negatively correlated with those of poverty and incomplete elementary education. These results suggest that municipalities with greater access to financial services are those that tend to have a smaller percentage of the population living in poverty, as well as better education. Further analysis will take a look at the relationships between all 20 indicators and construct a synthetic variable to describe the municipal situation from all dimensions of financial inclusion. 
Figure 3. Bivariate Correlation Matrix: One Variable per Financial Inclusion Dimension

\begin{tabular}{|l|c|c|c|c|c|}
\hline Variable & ACCESS & DEPOSIT & NO_PRIMARY & CONDUSEF & POVERTY \\
\hline ACCESS & 1 & 0 & 0 & 0 & 0 \\
\hline DEPOSIT & 0.2931 & 1 & -0.418 & 0.204 & -0.445 \\
\hline NO_PRIMARY & -0.228 & -0.4181 & 1 & -0.074 & 0.803 \\
\hline CONDUSEF & 0.073 & 0.204 & -0.0741 & 1 & -0.093 \\
\hline POVERTY & -0.303 & -0.445 & 0.803 & -0.093 & 1 \\
\hline
\end{tabular}

Fuente: Elaboración propia.

Finally, it is appropriate to highlight a characteristic of the database used for this study: the set of observations requires no probabilistic assumptions. This is because, first, the data is not based on a random sample, but represents the total population (all the municipalities in the country), and second, because the variables used are not random variables but the real observed values, that is, the official data reported for each of the municipalities in the country. Even though these indicators may be subject to errors related with quality of the data, they are the official measures reported by each institution. Therefore, the variability of the data is caused exclusively by the value of each observation.

\section{Results and Analysis}

\subsection{Computing the Financial Inclusion Index}

The set of units or individuals studied for the creation of this index is composed of the 2,456 municipalities in Mexico $\left\{\underline{x}_{1}, \underline{x}_{2}, \ldots, \underline{x}_{2456}\right\}$. Moreover, the set of variables $\left\{\underline{x}^{1}, \underline{x}^{2}, \ldots, \underline{x}^{20}\right\}$ consists of the 20 indicators that have been chosen to compute the financial inclusion index. From this moment, it is assumed that the variables $\underline{x}$ are centered and reduced for each of the municipalities (i.e., standardized).

The solution to $\max \operatorname{Var}(\underline{c})$ with constraint $\underline{a}^{T} \underline{a}=1$ is $V \underline{a}=\lambda \underline{a}$ where $\lambda_{i} \geq 0$ and $\underline{a}_{j} \perp \underline{a}_{k}$ (which consequently, implies that $\underline{c}^{j} \perp \underline{c}^{k}$ ). To find the eigenvectors and eigenvalues of the correlation matrix ${ }^{12} V=X^{T} D X$ as well as the graphs and principal component analysis, SPSS Statistics 20 was used. The resulting determinant of the correlation matrix has a value of $\$ 7.91 * 10^{-12}$. A low determinant for this matrix implies that there is at least a very strong relationship between two variables. What is initially trying to be explained in a space of twenty dimensions (because there are twenty indicators) is actually in a smaller space, thus, suggesting that the principal components will capture summarized information that is valuable.

On this analysis, the expression $\frac{\operatorname{Var}\left(\underline{\underline{c}}^{1}\right)+\ldots+\operatorname{Var}\left(\underline{\underline{c}}^{k}\right)}{p}$ indicates the proportion of the inertia (variance) explained by the first $k$ principal components. This measure is used to evaluate the quality of the graphs produced with the components. Even though the minimum acceptable values for this measure cannot be bluntly affirmed, when the ratio explained is satisfactory it is considered an adequate approach to the phenomenon.

$12 V$ is symmetric positive definite. 
The table below displays the total inertia (variance) explained by each of the principal components. In total, 20 components can be extracted.

Figure 4. Total Variance Explained by each Principal Component

\begin{tabular}{|c|c|c|c|}
\hline \multicolumn{2}{|c|}{ Component } & \multicolumn{2}{|c|}{ Initial eigenvalues } \\
\hline$\underline{c}^{i}$ & Total & \% of variance & \% cumulative \\
\hline 1 & 8.035 & 40.177 & 40.177 \\
2 & 3.492 & 17.46 & 57.637 \\
3 & 1.634 & 8.169 & 65.806 \\
4 & 1.213 & 6.064 & 71.87 \\
5 & 1.03 & 5.148 & 77.018 \\
6 & 0.857 & 4.283 & 81.301 \\
7 & 0.733 & 3.663 & 84.964 \\
8 & 0.639 & 3.195 & 88.159 \\
9 & 0.558 & 2.79 & 90.949 \\
10 & 0.479 & 2.394 & 93.342 \\
11 & 0.326 & 1.63 & 94.972 \\
12 & 0.292 & 1.46 & 96.432 \\
13 & 0.267 & 1.336 & 97.769 \\
14 & 0.192 & 0.959 & 98.728 \\
15 & 0.089 & 0.445 & 99.173 \\
16 & 0.072 & 0.358 & 99.531 \\
17 & 0.049 & 0.246 & 99.777 \\
18 & 0.031 & 0.157 & 99.934 \\
19 & 0.011 & 0.054 & 99.988 \\
20 & 0.002 & 0.012 & 100 \\
\hline
\end{tabular}

Fuente: Elaboración propia.

The first two principal components accumulate $57.6 \%$ of the total variance, i.e., $\left(\frac{\lambda_{1}}{p}+\frac{\lambda_{2}}{p}\right) * 100 \%=57.6 \%$. In the practice of multivariate statistics, this is considered to be an appropriate percentage. Further results confirm that the estimations provided contribute to a satisfactory interpretation of financial inclusion. For ease of the graphical explanation in a two-dimensional space, and due to the variance accumulation presented in the table, only the first two principal components will be used for the analysis. It is important to take into account that each additional component contributes with less variance than the last and that the components are uncorrelated with each other.

Since $\underline{c}^{k}$ is an element of the variable space, it can be considered as a synthetic variable. Accordingly, it is possible to obtain the correlation between the component $\underline{c}^{k}$ and any other element (indicator) of this particular space. The following table displays the correlation of each of the variables with principal components 1 and 2. These correlations allow to interpret which of the indicators are better explained by each of the components. 
168 Nueva Época REMEF (The Mexican Journal of Economics and Finance)

Figure 5. Correlations between the Variables and Principal Components $\underline{c}^{1}$ and $\underline{c}^{2}$

\begin{tabular}{|c|c|c|}
\hline $\begin{array}{l}\text { Number of branches (bank, cooperatives and } \\
\text { microfinance) and banking agents }\end{array}$ & 0.369 & 0.098 \\
\hline Bank presence & 0.548 & -0.085 \\
\hline Cooperative and Microfinance presence & 0.033 & 0.434 \\
\hline Banking agents presence & 0.277 & -0.12 \\
\hline Number of ATM.s & 0.672 & 0.095 \\
\hline Number of Points of Service (POS) & 0.632 & 0.125 \\
\hline Number of deposit accounts & 0.611 & 0.246 \\
\hline Number of loans and credit accounts & 0.492 & 0.336 \\
\hline Proportion of bank deposit accounts & 0.476 & -0.824 \\
\hline Proportion of bank credit accounts & 0.388 & -0.864 \\
\hline Banking agents presence & 0.277 & -0.12 \\
\hline Number of ATM.s & 0.672 & 0.095 \\
\hline Number of Points of Service (POS) & 0.632 & 0.125 \\
\hline Number of deposit accounts & 0.611 & 0.246 \\
\hline Number of loans and credit accounts & 0.492 & 0.336 \\
\hline Proportion of bank deposit accounts & 0.476 & -0.824 \\
\hline Proportion of bank credit accounts & 0.388 & -0.864 \\
\hline $\begin{array}{c}\text { Proportion of Cooperative and Microfinance } \\
\text { deposit accounts }\end{array}$ & -0.475 & 0.826 \\
\hline Banking agents presence & 0.277 & -0.12 \\
\hline Number of ATM.s & 0.672 & 0.095 \\
\hline Number of Points of Service (POS) & 0.632 & 0.125 \\
\hline Number of deposit accounts & 0.611 & 0.246 \\
\hline Number of loans and credit accounts & 0.492 & 0.336 \\
\hline Proportion of bank deposit accounts & 0.476 & -0.824 \\
\hline Proportion of bank credit accounts & 0.388 & -0.864 \\
\hline $\begin{array}{c}\text { Proportion of Cooperative and Microfinance } \\
\text { deposit accounts }\end{array}$ & -0.475 & 0.826 \\
\hline $\begin{array}{c}\text { Proportion of Cooperative and Microfinance } \\
\text { credit accounts }\end{array}$ & -0.386 & 0.871 \\
\hline Average adult ( 15 years or more) education in years & 0.917 & 0.152 \\
\hline Percentage of the population with lack of education & -0.847 & -0.12 \\
\hline Percentage of illiterate adults & -0.769 & -0.206 \\
\hline Adults with incomplete elementary education & -0.878 & -0.166 \\
\hline $\begin{array}{l}\text { Number of CONDUSEF.s technical and legal } \\
\text { advices and disputes }\end{array}$ & 0.172 & 0.071 \\
\hline Average income per municipality & 0.914 & 0.185 \\
\hline Incidence of poverty & -0.875 & -0.192 \\
\hline $\begin{array}{l}\text { Percentage of non-poor and non-vulnerable population } \\
\end{array}$ & 0.866 & 0.153 \\
\hline
\end{tabular}


On one hand, the table displays that the first principal component has a correlation higher than 0.4 (in absolute value) for most of the indicators. This component associates positive values to the indicators related with financial access such as branches, presence of institutions and financial products, while it associates negative values to indicators such as the population with lack of education, illiteracy, incomplete elementary education or in a poverty situation. On the other hand, the second component is more correlated to the variables that relate to banks, Cooperative and Microfinance institutions, specifically, to those that explain the proportion of the products in each municipality. Additionally, this component associates negative values to the variables that describe certain social and economic deficiencies of the population.

Values close to zero for the elements of the first and second components are municipalities that can be considered average. That is, municipalities that do not have a broad access to financial services, but also do not lack education or income severely.

With this data it is possible to construct a component plot, where the horizontal axis corresponds to $\underline{c}^{1}$ and the vertical axis to $\underline{c}^{2}$. In it, appreciation of which variables are more related to each other positively or negatively and which are uncorrelated is possible. Also, drawing lines from the origin of the plane to coordinates $\left(\operatorname{Corr}\left(\underline{c}^{1}, \underline{x}^{j}\right), \operatorname{Corr}\left(\underline{c}^{2}, \underline{x}^{j}\right)\right)$ for each of the variables allows to determine the angle between an indicator and the other, visually displaying how correlated they are.

Figure 6. Component Plot of $\underline{c}^{1}$ and $\underline{c}^{2}$

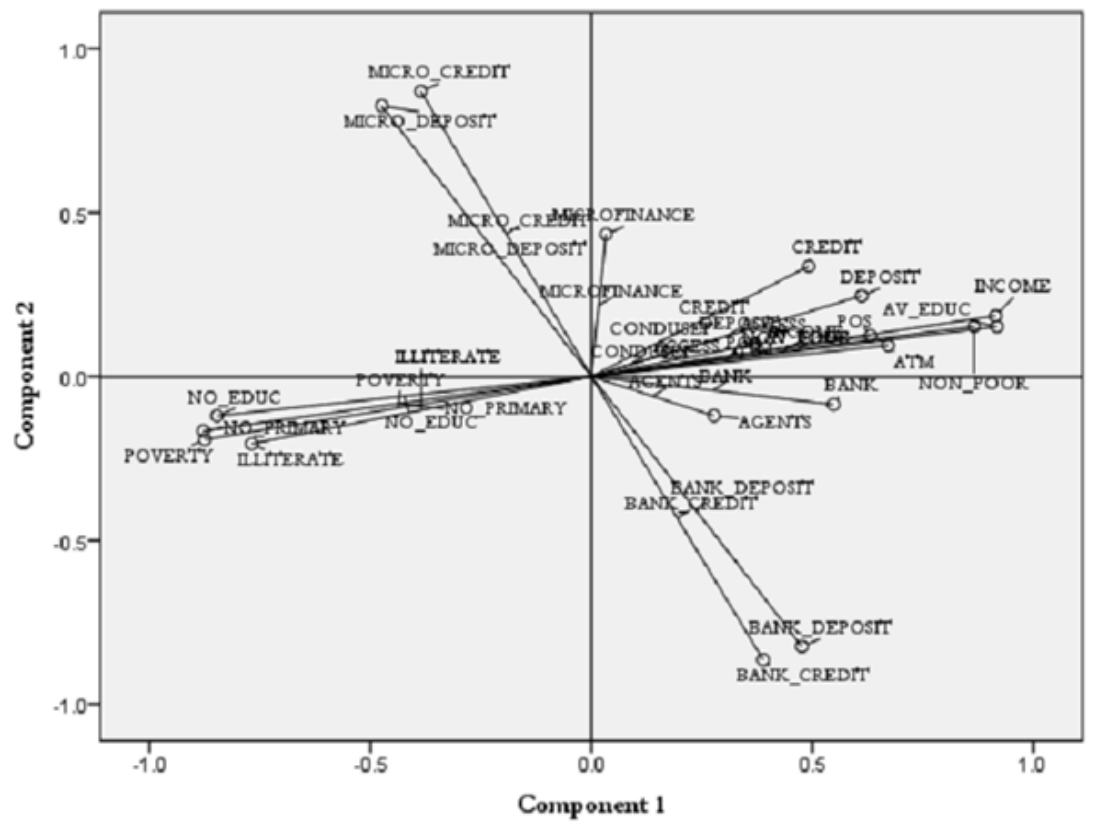

Fuente: Elaboración propia.

Studying the component plot, it is perceived that the indicators of access and usage of financial services (variables BANK, "ATM, POS, AGENTS, 
MICROFINANCE, CREDIT, DEPOSIT, CONDUSEF) form much smaller angles between them, and thus, are more and positively correlated because municipalities with a higher coverage of financial institutions are those with a greater amount of products. Also, the incidence of poverty (POVERTY) and low-education related variables (NO_EDUC, NO_PRIMARY, ILLITERATE) form small angles with each other, which means these variables are correlated positively as well. This is because the angle between the lines that were drawn tends to a number close to zero, and therefore, tends to a strong but positive correlation, ${ }^{13}$ since the cosine of angles near 0 tends to a value of 1 .

Furthermore, variables such as the proportion of deposits and credits (BANK_CREDIT, BANK_DEPOSIT, MICRO_CREDIT, MICRO_DEPOSIT) for any of the financial institutions tend to be uncorrelated with the rest of the variables of access, usage, education and social development. Angles close to 90 degrees imply cosine values close to 0 , and consequently, little or no correlation between the variables at all. This is easy to explain because the fact that financial services exist in a municipality generally does not imply that the Bank or the Cooperative and Microfinance institutions have the greatest share of this market. However, the plot displays that it is a fact that the variables of the proportion of deposit and credit products of Cooperatives and Microfinance institutions (MICRO_DEPOSIT, MICRO_CREDIT) are strongly correlated with municipalities in which the presence of such institutions (variable MICROFINANCE) is higher. This result is equivalent for the banking variables (BANK_DEPOSIT and BANK_CREDIT with variable BANK). These indicators do explain the reasons why there is a higher proportion of services provided by each of these institutions.

The same graph provides a fundamental result: variables belonging to the dimensions of access and usage of the financial services and greater average years of schooling (AV_EDUC), the non-poor and non-vulnerable population (NON_POOR) and a higher average income (INCOME) are strongly but inversely correlated to educational backwardness and poverty. This is explained because the angles between the lines of the variables form angles close to 180 degrees, implying that the cosine of that angle tends to -1 , that is, strong but negative correlation. This result suggests that the costs and minimum requirements of financial products are an essential barrier for people with insufficient income, along with the lack of education, which is also a barrier related to an adequate use of these services. Additionally, the impossibility of being able to fill out the required documentation applies for illiterate adults.

Thus, principal component $\underline{c}^{1}$ will receive the name of financial inclusion index, while the second, $\underline{c}^{2}$, will aid in the understanding of this phenomenon. The rest of the components are not included as part of this study because on one hand, they naturally accumulate much less variance of the data, and secondly, its interpretation does not represent an added value to the analysis ${ }^{14}$

13 In this type of multivariate study, the linear correlation between two variables $j$ and $k$ is equivalent to the cosine of the angle between them. This is because, in an analysis such as principal components, the cosine of two vectors equals the covariance of the vectors divided by the product of the standard deviations of each.

14 The third component's $\underline{c}^{3}$ highest correlation with a variable in absolute value is 0.5 . It 
The municipality with the highest financial inclusion index is the Cuauhtémoc borough in Mexico City: ${ }^{15}$ the capital's downtown. This municipality is attended by a considerable number of financial institutions given the presence of businesses and government institutions that use these services. This administrative unit's index value is followed by other boroughs of Mexico City and municipalities of Nuevo León like Monterrey, San Pedro Garza García and San Nicolás de los Garza. Other municipalities with the highest values include Solidaridad in Quintana Roo, whose county seat is Playa del Carmen; Guadalajara in Jalisco; Los Cabos in Baja California Sur; Tampico in Tamaulipas, among others. The highest values of the index are found for municipalities with higher development and tourism.

In contrast, the lowest value of the financial inclusion index belongs to the San Simón Zahuatlán municipality in Oaxaca. This is a rural municipality, with little adult population and a high percentage of the population in a poverty situation. Other municipalities in the same state and from states like Chiapas, Guerrero and Veracruz accompany this municipality with the lowest values. These four states are exactly the ones with the most pronounced social deficiencies (including insufficient education, quality of living, social security, health and the basic services). Also, they're the states with the highest incidence of extreme poverty, being Chiapas (32.8\%) the one with the highest percentage. ${ }^{16}$

Once the index has been computed, it is desirable to find a way to classify these municipalities according to their summarized financial inclusion.

\subsection{Classification of the municipalities by their degree of financial financial inclusion}

With aid of the financial inclusion index $\underline{c}^{1}$ and the auxiliary component $\underline{c}^{2}$, the next objective set was to classify the municipalities according to certain degree of financial inclusion that allows creating groups whose members are similar to each other and have characteristics that distinguish them between groups. Thus, three financial inclusion degrees (or levels) have been determined using a hierarchical cluster analysis: high, medium and low.

Using Ward's method as a criterion for creating clusters and the Squared Euclidean distance as a measure, the results of components 1 and 2 are used as the inputs for which similarities and dissimilarities are evaluated. Once this algorithm was applied, it was possible to plot the municipalities according to the value of their financial inclusion index and auxiliary component. Using the first component as the horizontal axis and the second component as the vertical axis, the plot distinguishes each of the groups as a result of applying hierarchical cluster analysis.

assigns positive values to variables of financial services and lag but with much lower correlations. This component explains about $8 \%$ of the variance of the data, so it is not taken into account for the analysis.

15 Mexico City is divided into sixteen boroughs for administrative purposes. Even though these boroughs do not have regulatory powers or are fully autonomous like municipalities, each is considered a municipality when reporting data at this level.

16 Consejo Nacional de Evaluación de la Política de Desarrollo Social (2011), Informe de Evaluación de la Política de Desarrollo Social 2011, Mexico, p. 23. 
7. Municipalities by their Degree of Financial Inclusion with Coordinates $\left(\underline{c}_{i}^{1}, \underline{c}_{i}^{2}\right)$

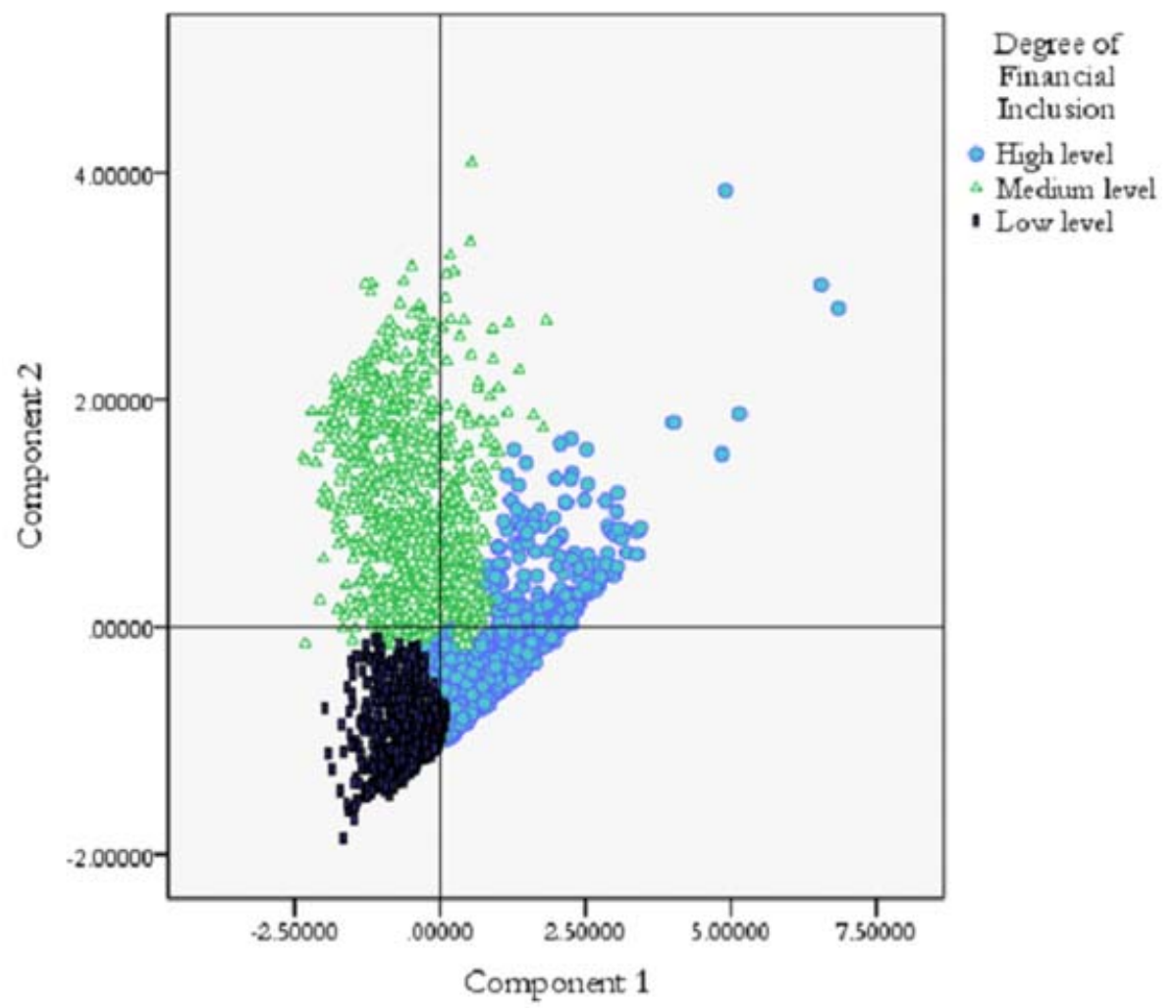

Fuente: Elaboración propia.

The groups are now perfectly distinguishable. The first group (marked with circles) corresponds to those municipalities with a positive and higher value of the financial inclusion index in comparison with groups 2 (marked with triangles) and 3 (marked with rectangles). The latter (groups 2 and 3) contain municipalities whose financial inclusion index is not necessarily higher for some than others, but the auxiliary component $\underline{c}^{2}$ explains its differences: the graph suggests that municipalities in group 2 are more attended by Cooperative and Microfinance institutions and have less education and economic deficiencies than those that characterize group 3 .

Given this analysis, three degrees of financial inclusion are determined as follows: group 1 corresponds to municipalities with a high level of financial inclusion, group 2 to municipalities with a medium level of financial inclusion and group 3 to those with a low level. 


\subsection{Municipal Analysis}

Once that the degree of financial inclusion has been assigned for each municipality, an analysis of each of these groups allows comparisons between them according to their financial and social characteristics.

Figure 8. Municipalities and Adult Population by Degree of Financial Inclusion

\begin{tabular}{|c|c|c|c|c|}
\hline $\begin{array}{c}\text { Financial } \\
\text { Inclusion }\end{array}$ & Municipalities & $\begin{array}{c}\text { Percentage of } \\
\text { municipalities }\end{array}$ & $\begin{array}{c}\text { Adult } \\
\text { population }\end{array}$ & $\begin{array}{c}\text { Percentage } \\
\text { of adults }\end{array}$ \\
\hline High & 884 & $36 \%$ & $63,130,529$ & $79.1 \%$ \\
\hline Medium & 848 & $35 \%$ & $9,834,476$ & $12.3 \%$ \\
\hline Low & 724 & $29 \%$ & $6,855,737$ & $8.6 \%$ \\
\hline
\end{tabular}

Fuente: Elaboración propia.

Geographic and demographic distribution in the country is complex. Although each group has a percentage of municipalities between $29 \%$ and $36 \%$, most of the adult population (79.1\%) lives in municipalities with a high level of financial inclusion. However, this does not mean that all these adults have access to the financial services they require, it only indicates that they have the possibility of doing so. Moreover, the rest of the municipalities of the country account for a medium and low level of financial inclusion, even though only $21 \%$ of the adult population inhabits them. These results suggest that there is infrastructure (branches or banking agents) in municipalities inhabited by the vast majority of the adult population, but the products are not all that suitable for their inclusion in the financial system.

Municipalities with a high level of financial inclusion are characterized for having branches, banking agents, ATM's and POS per 10,000 adults in higher proportions than the reported national level, ${ }^{17}$ higher presence of the banking institutions and a more considerable amount of deposit and credit financial products per 10,000 adult. ${ }^{18}$ In contrast, municipalities with a low level of financial inclusion have barely one access point, ${ }^{19}$ and despite having a channel through which they can access the financial system, they can often only perform basic operations such as payments of the basic services (electricity, water, telephone), placing deposits or cashing checks, activities which do not entail them as members of the financial system. A first step for this individuals is that they are holders of an account and that they can maintain it over time.

17 Municipalities with a high level of financial inclusion have 3.81 access points, 5.42 ATM's and 76.7 POS per 10,000 adults: these indicators are higher than the national computed values (3.29 access points, 4.52 ATM's and 62.7 POS per 10,000 adults).

18 When comparing indicators by the level of financial inclusion with the national values, it is observed that municipalities with a high level of financial inclusion have more deposit (13,166 products per 10,000 adults) and credit (4,755 per 10,000 adults) products per 10,000 adults than the national level (11,742 and 4,125 per 10,000 adults, respectively).

19 Access indicators for the municipalities with a low level of financial inclusion are: 1.01 access points, 0.49 ATM's and 2.44 POS per 10,000 adults. 
174 Nueva Época REMEF (The Mexican Journal of Economics and Finance)

Figure 9. Presence of Institutions by Degree of Financial Inclusion

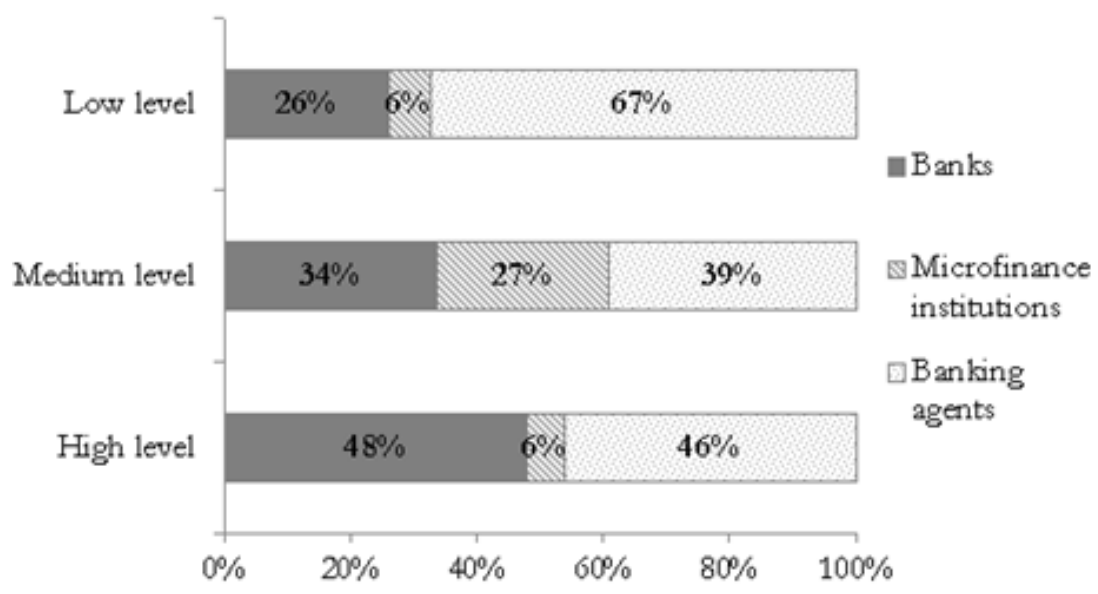

Fuente: Elaboración propia.

Cooperative and Microfinance institutions mainly attend municipalities with a medium level of financial inclusion ${ }^{20}$. Even though this suggests that their objectives are well on track, these institutions, along with banks, must include reaching wider segments of the population with new and innovative financial services as part of their strategy.

Figure 10. Education and Poverty by degree of Financial Inclusion

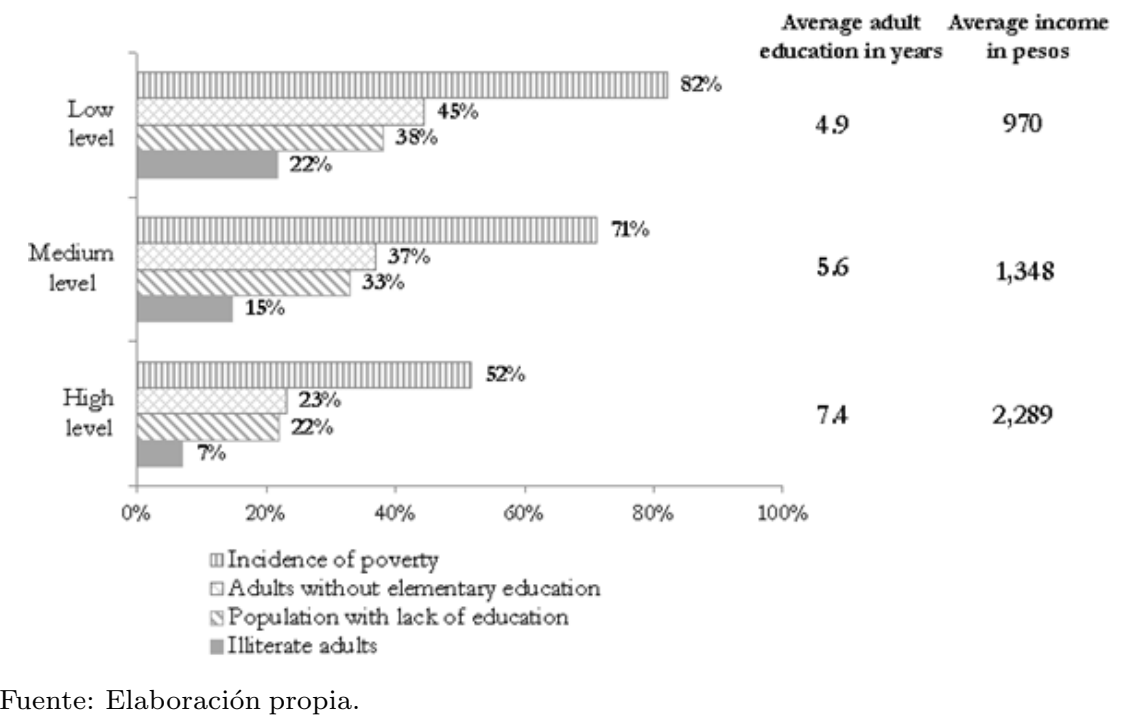

20 In fact, Cooperative and Microfinance institutions have higher values of the deposit and credit products per 10,000 adults in municipalities with a medium level of financial inclusion than those with a high or low level, where banks dominate the market. 
Municipalities with a high level of financial inclusion also account for a higher level of education (average adult education in years) and less presence of adult illiteracy and incomplete elementary school studies. These are also the only municipalities that have an attention module of CONDUSEF that people can attend to, ${ }^{21}$ and of course, they have a higher average income ${ }^{22}$ than the rest of the municipalities in the country. In contrast, municipalities with a lower degree of financial inclusion have the largest amount of population living in poverty $(82.12 \%$, compared to the national level of $46.2 \%)$ and a higher number of social deficiencies. The population that does not have access to the basic services of living and an adequate income uses it to meet these needs, and therefore, does not have the money or interest in applying for a financial product. Lower incomes are a barrier to some financial services such as credits. Also, some deposit and savings accounts charge high commissions if the holders do not have a minimum balance in their account.

To complement this analysis, the following map of Mexico displays each of the municipalities according their degree of financial inclusion. The map was produced with INEGI's IRIS 4.2 software.

Figure 11. Presence of Institutions by Degree of Financial Inclusion

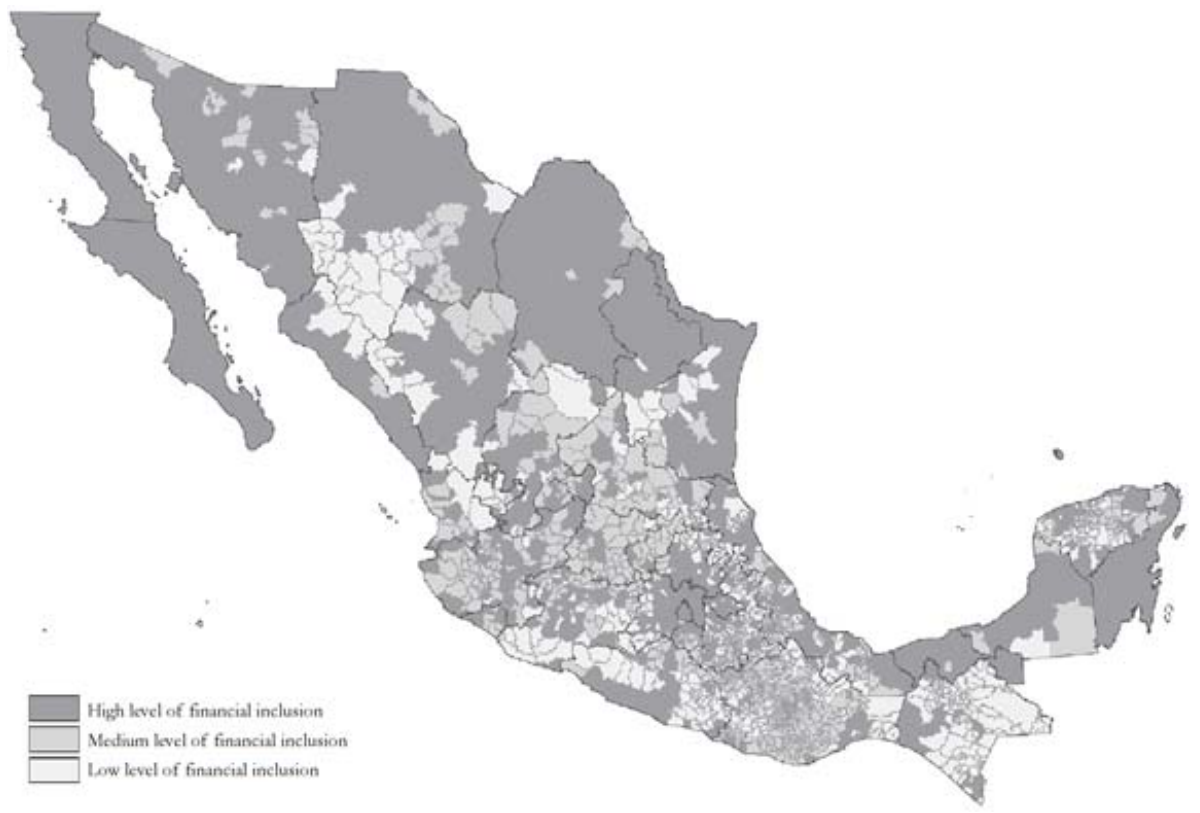

Fuente: Elaboración propia.

21 Municipalities with a high level of financial inclusion compose the only group that shows positive values for the indicator of CONDUSEF's technical and legal advices and disputes (169.38 per 10,000 adults).

22 Municipalities with a low level of financial inclusion have an average income of $\$ 870$ Mexican pesos, while this indicator for municipalities with a medium level is $\$ 1,348$. On the other hand, the average income for municipalities with a high level of financial inclusion is $\$ 2,289$. 
176 Nueva Época REMEF (The Mexican Journal of Economics and Finance)

\subsection{State Analysis}

Studying the percentage of municipalities that have a high, medium or low level of financial inclusion for each of Mexico's 32 states can suggest which of them appear to be more excluded from the financial system.

Figure 12. Proportion of Municipalities by Degree of Financial Inclusion and State

\begin{tabular}{|c|c|c|c|c|}
\hline Aguascalientes & 11 & $36 \%$ & $64 \%$ & $0 \%$ \\
\hline Baja California & 5 & $100 \%$ & $0 \%$ & $0 \%$ \\
\hline Baja California Sur & 5 & $100 \%$ & $0 \%$ & $0 \%$ \\
\hline Campeche & 11 & $64 \%$ & $27 \%$ & $9 \%$ \\
\hline Coahuila & 38 & $87 \%$ & $13 \%$ & $0 \%$ \\
\hline Colima & 10 & $50 \%$ & $50 \%$ & $0 \%$ \\
\hline Chiapas & 118 & $17 \%$ & $3 \%$ & $80 \%$ \\
\hline Chihuahua & 67 & $49 \%$ & $18 \%$ & $33 \%$ \\
\hline Distrito Federal & 16 & $100 \%$ & $0 \%$ & $0 \%$ \\
\hline Durango & 39 & $54 \%$ & $21 \%$ & $26 \%$ \\
\hline Guanajuato & 46 & $11 \%$ & $87 \%$ & $2 \%$ \\
\hline Guerrero & 81 & $27 \%$ & $19 \%$ & $54 \%$ \\
\hline Hidalgo & 84 & $57 \%$ & $8 \%$ & $35 \%$ \\
\hline Jalisco & 125 & $40 \%$ & $52 \%$ & $8 \%$ \\
\hline México & 125 & $85 \%$ & $2 \%$ & $14 \%$ \\
\hline Michoacán & 113 & $30 \%$ & $50 \%$ & $20 \%$ \\
\hline Morelos & 33 & $48 \%$ & $52 \%$ & $0 \%$ \\
\hline Nayarit & 20 & $40 \%$ & $45 \%$ & $15 \%$ \\
\hline Nuevo León & 51 & $90 \%$ & $0 \%$ & $10 \%$ \\
\hline Oaxaca & 570 & $7 \%$ & $60 \%$ & $32 \%$ \\
\hline Puebla & 217 & $21 \%$ & $30 \%$ & $49 \%$ \\
\hline Querétaro & 18 & $17 \%$ & $78 \%$ & $6 \%$ \\
\hline Quintana Roo & 9 & $89 \%$ & $11 \%$ & $0 \%$ \\
\hline San Luis Potosí & 58 & $24 \%$ & $55 \%$ & $21 \%$ \\
\hline Sinaloa & 18 & $78 \%$ & $6 \%$ & $17 \%$ \\
\hline Sonora & 72 & $75 \%$ & $22 \%$ & $3 \%$ \\
\hline Tabasco & 17 & $94 \%$ & $6 \%$ & $0 \%$ \\
\hline Tamaulipas & 43 & $67 \%$ & $14 \%$ & 19 \\
\hline Tlaxcala & 60 & $83 \%$ & $5 \%$ & $12 \%$ \\
\hline Veracruz & 212 & $33 \%$ & $31 \%$ & 36 \\
\hline Yucatán & 106 & $27 \%$ & $22 \%$ & $51 \%$ \\
\hline Zacatecas & 58 & $45 \%$ & $38 \%$ & $17 \%$ \\
\hline
\end{tabular}

Fuente: Elaboración propia.

Most municipalities in 27 states have a high or medium level of financial inclusion. While 17 states are dominated by municipalities with a high level of financial inclusion, 9 are dominated by municipalities with a medium one. Colima is the only state that has half of its municipalities with a high level of 
financial inclusion and the other half with a medium level. However, the states of Chiapas, Guerrero, Puebla, Veracruz and Yucatán are the five states where most of the municipalities have a low level of financial inclusion, with Chiapas as the state with the highest percentage $(80 \%)$.

When principal component analysis is performed with the observations of the 32 states, it is obtained that Mexico City, Baja California and Baja California Sur are the states with the highest value of the first principal component $\underline{c}_{i}^{1, S}$ (state level). Oaxaca, followed by Chiapas, Guerrero, Michoacán, Puebla and Guanajuato, are the states with the lowest value. These results are quite consistent with those obtained by merely analyzing the type of municipalities that predominate in each state. Financial exclusion and a lower value of the first principal component are closely related to the states whose social and educational backwardness is much more marked, while those who have more access to financial services reflect smaller values for these indicators. In fact, according to CONAPO, the states of Guerrero, Chiapas and Oaxaca have the highest level of poverty due to the shortages and hardships that most of their population suffers. ${ }^{23}$

\subsection{Regional Analysis}

Based on the Mexican government's National Development Plan ${ }^{24}$ the country can be divided into five major geographical regions: the Central region, with Mexico City, Hidalgo, the state of Mexico, Morelos, Tlaxcala and Querétaro; the Central-west region, which includes the states of Aguascalientes, Colima, Guanajuato, Jalisco, Michoacán, Nayarit, San Luis Potosí and Zacatecas; the Northeast region, with the states of Coahuila, Chihuahua, Durango, Nuevo León and Tamaulipas; the Northwest region, with the states of Baja California, Baja California Sur, Sinaloa and Sonora; and finally, the Southeast region, with Campeche, Chiapas, Guerrero, Oaxaca, Puebla, Quintana Roo, Tabasco, Veracruz and Yucatán.

Performing a similar analysis for the regions of the country, it is found that municipalities with a higher level of financial inclusion predominate in the Northwest, Northeast and Central regions, while municipalities with a medium level predominate in the Central-west part of the country. ${ }^{25}$ Needless to say, the Southeast region is mostly dominated by a low level of financial inclusion ( $42 \%$ of its municipalities have a low level).

This is confirmed with the fact that the Northeast region has the highest value of the access points indicator per 10,000 adults (4.70 per 10,00 adults), while the Central region has the highest indicators for financial products $(15,290$ deposit products and 5,990 credit products per 10,000 adults) and CONDUSEF's technical and legal advices and disputes (306.26 per 10,000

\footnotetext{
23 Consejo Nacional de Población (2010), Índice de marginación por entidad federativa y municipio 2010, Mexico, p. 25.

24 Gobierno de los Estados Unidos Mexicanos (2007), Primer informe de gobierno, Presidencia de la República, México, pp. 195-196.

$2571 \%$ of the Central part of the country's municipalities have a high level of financial inclusion; $68 \%$ of the Northeast and $78 \%$ of the Northwest do too. On the other hand, $54 \%$ of the Center-west region's municipalities have a medium level of inclusion.
} 
adults). In contrast, the Southeast region possesses the lowest value for all indicators, ${ }^{26}$ thus, confirming this is the geographical region with the most pronounced financial exclusion. Also, Cooperative and Microfinance institutions attend this and the Central-west region in a higher proportion (10\% of the access points of these regions belong to these institutions) in comparison with the rest (no more than $6 \%$ of the access points of the other regions belong to Cooperative or Microfinance institutions).

Financial exclusion in the Southeast region is also evidenced by the fact that roughly $41 \%$ of its municipalities have an access point to financial services, whilst the rest of the country's regions have an infrastructural coverage of at least $73 \%$. Finally, this region demonstrates to have the most pronounced social and economic deficiencies in the country: the least average years of schooling (5.4), the highest percentage of the population living in poverty $(76 \%)$, the highest illiteracy (19\%), severe lack of education (35\%) and the most adults without complete elementary school (40\%).

\section{Concluding Remarks}

Financial inclusion has been identified as a measurable multidimensional phenomenon. In practice, its measurement should not be limited to studying the number of financial institutions and products, but allowed to include features of social, political and economic scope. This study shows evidence that there are existent relationships between education, income, poverty and health with financial inclusion related data.

The financial inclusion index presented has several advantages over other indices that have been proposed before: first, it is constructed with principal component analysis and does not subjectively establish the ideal or maximum value the variables should have for each of the dimensions; second, it incorporates information from financial institutions (Cooperative and Microfinance) that were not previously considered; third, it covers five major dimensions of the phenomenon that not only account for infrastructure and product-related indicators; finally, the index allows to classify the municipalities into groups according to their degree of financial inclusion, revealing which characteristics are shared among them.

According to the results, adult population is heavily concentrated in municipalities with a high level of financial inclusion. This does not imply that most of these adults are candidates for a financial product of their choice, but it is evidence that broadening the financial infrastructure to the rest of the municipalities is not enough to serve the excluded population.

Efforts should be directed to designing new and innovative financial products that meet the needs of these segments of the population and that can directly and positively impact their quality of life. Encouraging the habits of saving and investing allows for a better preparation and a more stable future of individuals. Additionally, it employs more complex schemes that can aid in addressing future expenses and needs such as education or incidentals related to health, while avoiding the decline of all or part of their income.

\footnotetext{
26 The Southeast region has 2.26 access points, 8,129 deposit products, 2,746 credit products and 50.32 CONDUSEF's technical and legal advices and disputes per 10,000 adults.
} 
It is also important to note that the lack of education is a fundamental barrier to the access of financial services. Accompanied by illiteracy and other social needs that distinguish the population in conditions of poverty, it marginalizes individuals' opportunities far beyond financial inclusion: these deficiencies also impact their daily development in today's society.

The Southeast region suffers the greatest economic and social deprivation, suggesting that the conditions of poverty and insufficient income exclude the individuals from the ability to access financial services, regardless of the absence of financial institutions in a considerable portion of its territory. This only indicates that even when the financial system's infrastructure is expanded to this region, most of its population would probably be unable to obtain a financial product that can help improve their quality of life. It is therefore necessary to develop products fitted to their needs which can provide real benefits. Hand in hand with this, education in the country must be improved.

However, the task is not limited to promoting new financial products. A significant fraction of the society is not interested in being part of the financial system due to the mistrust they have for the institutions. Thus, the creation of financial education strategies that encourage people to join the system and that instruct them the basic principles on the use of these mechanisms is the first step to reduce the self-exclusion of these individuals. Still, informing the voluntarily excluded population must not be the only objective, but also to create financial education programs that teach the appropriate use of the services, especially at the basic levels.

The population with higher income and education is the one that primarily benefits from the services that financial institutions offer, yet millions of people are excluded from the Mexican financial system every day. Proposing indicators and measures to study and subsequently develop policies to benefit these segments of the population is a bet towards new opportunities: it allows both the families and the country as a whole to prosper, towards a more equitable growth. An efficient identification of the ongoing financial inclusion in the country leaves the door open not only to improving the quality of life for each individual, but also to position Mexico as a role model: a country of opportunities, in which the great economic disparities are a matter fought through numerous efforts.

\section{References}

Alliance for Financial Inclusion (2011), Measuring financial inclusion in Mexico: CNBV's approach to obtaining better data for decision-makers, AFI Case Studies, Thailand.

Ardic, O., M. Heimann, and N. Mylenko (2011), Access to financial services and the financial inclusion agenda around the world: a cross-country analysis with a new data set, World Bank Policy Research Working Paper 5537, The World Bank, United States.

Banco Central do Brasil (2011), Relatório de inclusão financeira número 2, Brazil.

Beck, T., A. Demirguc-Kunt, and M. Soledad Martinez (2005), Access to and use of banking services across countries, World Bank Policy Research Working Paper 3754, The World Bank, United States.

Center for Financial Inclusion at ACCION International (2009), Informe oficial del Proyecto de Inclusión Financiera en 2020 del Centro para la Inclusión Financiera en ACCION International, Mexico. 
180 Nueva Época REMEF (The Mexican Journal of Economics and Finance)

Comisión Nacional Bancaria y de Valores (2010), Modelos de Negocio para la Inclusión Financiera 1: Corresponsales bancarios, el papel de los comercios independientes y las redes de distribución de productos, Mexico.

CNBV (2009), Primer reporte de inclusión financiera, Mexico.

CNBV (2010), Segundo reporte de inclusión financiera, Mexico.

CNBV (2011), Tercer reporte de inclusión financiera, Mexico.

Comisión Nacional para la Protección y Defensa de los Usuarios de Servicios Financieros (2010), Anuario Estadístico 2010, Mexico.

Consejo Nacional de Evaluación de la Política de Desarrollo Social (2011), Informe de Evaluación de la Política de Desarrollo Social 2011, Mexico.

Consejo Nacional de Evaluación de la Política de Desarrollo Social (2010), Lineamientos y criterios generales para la definición, identificación y medición de la pobreza, Diario Oficial de la Federación, Mexico.

Consejo Nacional de Población (2010), Índice de marginación por entidad federativa y municipio 2010, Mexico.

Consultative Group to Assist the Poor (2010), Financial Access 2010: The State of Financial Inclusion Through the Crisis, The World Bank, United States.

Gobierno de los Estados Unidos Mexicanos (2007), Primer informe de gobierno, Presidencia de la República, Mexico.

Instituto Nacional para la Evaluación de la Educación (2008), Panorama Educativo de Mexico. Indicadores del Sistema Educativo Nacional 2008, Mexico.

Johnson, R. and D. Wichern (2002), Applied multivariate statistical analysis, Prentice Hall, 5 th ed., United States.

Kumar, V., et al. (2005), Introduction to Data Mining, Addison Wesley, United States.

Caskey, P., J. Clemente and T. Solo (2006), The Urban Unbanked in Mexico and the United States, World Bank Policy Research Working Paper 3835, The World Bank, United States.

Peña, D. (2002), Análisis de datos multivariantes, McGraw-Hill, Spain.

Rangarajan Committee (2008), Report of the Committee on Financial Inclusion, Government of India, India.

Sarma, M. (2010), Index of Financial Inclusion, Discussion Paper 10-05, Jawaharlal Nehru University, India.

Secretaría de Hacienda y Crédito Público (2011), Acuerdo por el que se crea el Consejo Nacional de Inclusión Financiera, Diario Oficial de la Federación, Mexico. 